\title{
Towards the Development of an Immuno MALDI (iMALDI) Mass Spectrometry Assay for the Diagnosis of Hypertension
}

\author{
Jennifer D. Reid, ${ }^{\mathrm{a}, \mathrm{b}}$ Daniel T. Holmes, ${ }^{\mathrm{c}}$ D. Randal Mason, ${ }^{\mathrm{a}, \mathrm{b}}$ \\ Brinda Shah, ${ }^{\mathrm{a}, \mathrm{b}}$ and Christoph H. Borchers ${ }^{\mathrm{a}, \mathrm{b}}$ \\ ${ }^{a}$ University of Victoria-Genome British Columbia Proteomics Centre, University of Victoria, Victoria, British \\ Columbia, Canada \\ ${ }^{\mathrm{b}}$ Department of Biochemistry and Microbiology, University of Victoria, Victoria, British Columbia, Canada \\ ${ }^{\mathrm{c}}$ Department of Pathology and Laboratory Medicine, University of British Columbia, St. Paul's Hospital, \\ Vancouver, British Columbia, Canada
}

The renin-angiotensin-aldosterone system (RAAS) plays an essential role in the regulation of plasma volume and arterial blood pressure. One of the most common diseases of the RAAS is the autonomous production of aldosterone by the adrenal glands, caused by either bilateral adrenal hyperplasia or an aldosterone-producing adenoma. This condition, known as primary aldosteronism, is a treatable and often curable form of hypertension. The measurement of plasma renin activity (PRA), as determined by radioimmunoassay for angiotensin I is essential to the diagnosis of primary aldosteronism. However, accurate determination of PRA is often hampered by low plasma concentrations of angiotensin I. Here, we report the use of immunoMALDI (iMALDI) as a highly sensitive and specific method for the absolute quantitation of angiotensin I in plasma. iMALDI permits concentration determination by affinity-capture of angiotensin I and a stable-isotopically labeled standard (SIS) peptide on immobilized antipeptide antibodies. The affinity beads are placed on the MALDI target, permitting automated analysis of large numbers of patient samples. Pretreatment of the plasma is not required, and this method is suitable for the accurate determination of angiotensin I in whole plasma. The calibration curve generated using this method was linear over a 50-fold concentration range in plasma, with a correlation coefficient of 0.984 . MS/MS sequence confirmation provides absolute specificity. The iMALDI angiotensin I assay, therefore, has the potential to be developed into a method for determining PRA that has advantages in time, in specificity, and in safety. (J Am Soc Mass Spectrom 2010, 21, 1680-1686) (C) 2010 American Society for Mass Spectrometry

$\mathrm{H}$ ypertension is a serious and often symptomless condition that currently affects $\sim 1$ billion people [1]. Because hypertension increases the chance of heart attack, heart failure, stroke, and kidney disease, it is imperative that treatable and/or curable forms of hypertension be identified early and appropriately managed. The renin-angiotensin-aldosterone system (RAAS) plays an important role in the regulation of aldosterone, and consequently, maintenance of arterial pressure and development of certain hypertensive diseases. This system is regulated by the proteolytic enzyme renin, which is released into the plasma from the juxtaglomerular cells of the afferent arteriole of the renal glomerulus in response to low arterial pressure, direct adrenergic stimulation or reductions in $\mathrm{Na}^{+}$or $\mathrm{Cl}^{-}$ concentrations in renal tubular fluid [2]. Renin cleaves the decapeptide angiotensin I from angiotensinogen, an $\alpha-2$

Address reprint requests to Dr. C. H. Borchers, University of VictoriaGenome British Columbia Proteomics Centre, 3101-4464 Markham St, Victoria, BC V8Z 7X8, Canada. E-mail: christoph@proteincentre.com globular protein, which is then converted into an octapeptide, angiotensin II, principally but not exclusively by the action of angiotensin converting enzyme (ACE). While angiotensin I has no physiologic effects, angiotensin II is a powerful vasoconstrictor and regulator of sodium reabsorption and water retention, thereby increasing blood pressure. Angiotensin II also stimulates the release of aldosterone from the adrenal gland, which further increases sodium reabsorption and water retention. The resulting increase in arterial pressure then signals the kidneys to decrease renin secretion.

Dysregulation of the RAAS leads to several treatable causes of hypertension including, primary aldosteronism (e.g., bilateral adrenal hyperplasia, aldosterone producing adenoma, glucocorticoid remediable hypertension), and secondary aldosteronism (e.g., renal artery stenosis). Essential to the diagnosis of these disorders is the analytical determination of plasma renin activity (PRA), which is usually determined from the rate of enzymatic cleavage of angiotensin I from angiotensinogen during a fixed incubation period ranging from 
3 to $18 \mathrm{~h}$, depending on the method used. Commerciallyavailable competitive-binding radioimmunoassays (RIAs) are widely used for the measurement of PRA for clinical purposes. However, limitations of RIAs include a requirement for the use of radioisotopes, nonlinear calibration curves, narrow linear ranges, and analytical interferences from peptides related to angiotensin I.

Mass spectrometry (MS)-based proteomics is a highly sensitive technology that provides absolute specificity through accurate molecular weight determination and peptide sequencing, thereby preventing misdiagnosis, which could result from antibody crossreactivity. In addition, radioactive isotopes are not required, making MS a safer option. The iMALDI technique combines antibody affinity enrichment with MS, resulting in the highly sensitive and specific analysis of target molecules. Incorporation of stableisotopically labeled peptides as internal standards permits absolute quantitation.

We have previously shown the application of the iMALDI method for detection and quantitation of epidermal growth factor receptor (EGFR) [3] and Francisella tularensis [4]. In this paper, we describe the application of this technique to the quantitation of angiotensin I in whole human plasma.

\section{Materials and Methods}

\section{Chemicals and Reagents}

Polyclonal antibodies to angiotensin I were obtained by immunizing rabbits with angiotensin-I/albumin complexes in Freund's adjuvant [5]. Mouse monoclonal antibodies to angiotensin I (ab54212, $1 \mathrm{mg} / \mathrm{mL})$ were purchased from AbCam (Cambridge, MA, USA). Magnetic Protein G Dynabeads (Invitrogen, Oslo, Norway) were precipitated in the manufacturer's detergentcontaining storage buffer with a magnet. The supernatant was removed, and the beads were washed in 1X PBS to remove as much of the storage buffer as possible (three washes in $50-\mu \mathrm{L}$ aliquots) by vortexing the beads in buffer and removing the supernatant. A volume of $5 \mu \mathrm{L}$ of beads was used for each reaction. Antibodies ( $2 \mu \mathrm{L}$ polyclonal antibody per reaction, or $1 \mu \mathrm{g}$ monoclonal antibody) were immobilized on Protein G Dynabeads in 1X PBS, pH 7.4 for $1 \mathrm{~h}$ at room temperature. The antibody bead conjugation is done in batches so that multiple analyses can be performed in parallel. Excess antibody is removed by washing the beads in $1 \times$ PBS (three washes in $50 \mu \mathrm{L} 1 \times$ PBS). Beads are resuspended in $1 \times$ PBS ( $5 \mu \mathrm{L}$ buffer per reaction) and then aliquoted into the individual samples.

Angiotensin I was synthesized with a stable-isotopically coded arginine residue (+10 Da) (DRVYIHPFHL) at the University of Victoria Genome BC Proteomics Centre, Victoria, Canada, according to our previously described protocols $[6,7]$.

\section{Sample Preparation}

The human plasma used for these experiments was provided by a donor with unknown diagnosis of arterial pressure related disease. Blood was collected in a BD Lavender EDTA tube. Plasma was separated, stored at $-80{ }^{\circ} \mathrm{C}$, and thawed at $4{ }^{\circ} \mathrm{C}$. A 1 -h incubation at $37^{\circ} \mathrm{C}$ was used to generate angiotensin I through cleavage of angiotensinogen by renin (the angiotensin I generation period). Note: Because angiotensin converting enzyme (ACE) inhibitors were not added to the plasma samples in these proof-of-concept experiments, the quantitation of angiotensin I as described in this paper should not be confused with the actual measurement of PRA in human plasma. ACE would reduce the concentration of angiotensin I by cleaving it to angiotensin II, so adding ACE inhibitors would be expected to increase the level of angiotensin I in the plasma sample. However, we recognize that although the EDTA in the plasma collection tubes would be expected to inhibit ACE, a zinc metalloenzyme, for accurate determination of PRA, we will need to verify that all ACE in the sample is inhibited. In addition, capture of the analyte by the antibody beads prevents enzymatic cleavage of angiotensin I to angiotensin II by steric hindrance [8].

Before direct MALDI TOF/TOF analysis of whole human plasma, Millipore (Billerica, MA, USA) ZipTipC18 pipette tips were used to desalt and concentrate the sample according to the manufacturer's protocol. The ZipTips were primed with $100 \%$ acetonitrile $(10 \mu \mathrm{L})$ by aspirating solution into the tip and dispensing (repeated twice). A $50 \%$ acetonitrile solution $(10 \mu \mathrm{L})$ was then aspirated into the tip twice, followed by $10 \mu \mathrm{L}$ of $0.1 \%$ TFA three times. Sample $(10 \mu \mathrm{L})$ was then aspirated and dispensed for five cycles. A wash solution of $0.1 \%$ TFA was then aspirated three times. Trapped peptides were eluted with $10 \mu \mathrm{L}$ of MALDI matrix solution, and $1 \mu \mathrm{L}$ was spotted onto the MALDI target.

\section{iMALDI}

In the iMALDI workflow for quantitation of angiotensin I (Figure 1), a stable-isotope coded version of angiotensin I (synthesized by the UVic Genome BC Proteomics Centre) is used as an internal standard. Anti-peptide affinity beads are incubated with the plasma sample and the internal standard for 1 to $18 \mathrm{~h}$ at $4{ }^{\circ} \mathrm{C}$ (the angiotensin I capture period) [3, 4, 7, 9-11]. Endogenous angiotensin I and the internal standard are affinity captured from the plasma solution by the antibody-bound beads, which are then placed onto a MALDI 384-well plate for mass spectrometry analysis. Plasma samples are kept at $4{ }^{\circ} \mathrm{C}$ throughout the iMALDI workflow to prevent cleavage of angiotensinogen to angiotensin I by renin.

In these experiments, a $20-\mu \mathrm{L}$ aliquot of whole human plasma (non-digested) was incubated with immobilized antibody beads ( $5 \mu \mathrm{L}$ slurry) overnight at $4{ }^{\circ} \mathrm{C}$. 

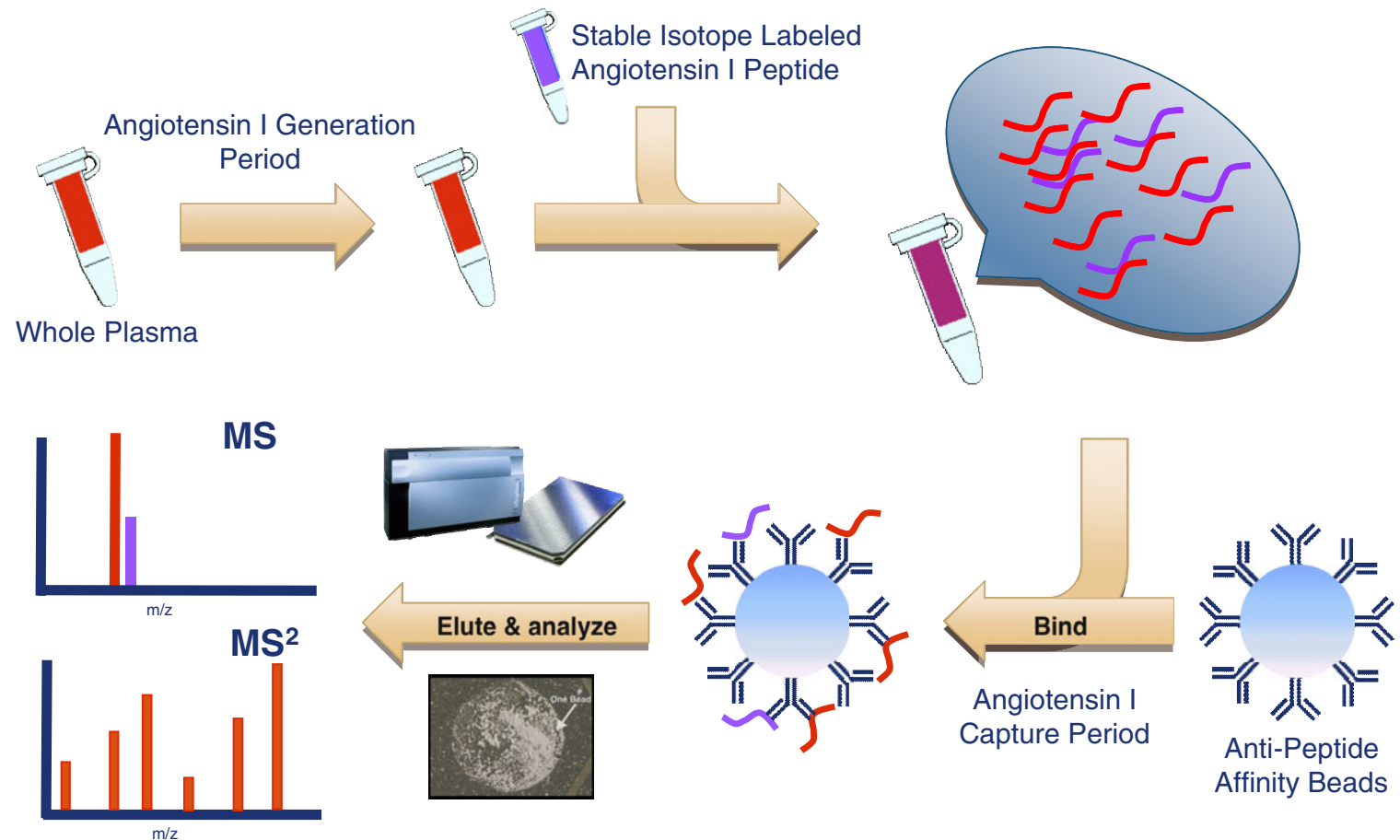

Figure 1. iMALDI workflow for angiotensin I. Whole human plasma is incubated at $37^{\circ} \mathrm{C}$ to allow enzymatic cleavage of angiotensinogen to angiotensin I by renin. The internal standard is then added to the plasma, and the sample is incubated with anti-angiotensin I antibody conjugated beads. The endogenous angiotensin I and the internal standard are immunoprecipitated, and the beads are placed directly on a MALDI target plate in a microarray format. CHCA matrix is applied to elute the peptide from the antibody permitting MALDI MS analysis. The relative abundances of the molecular ion signals corresponding to endogenous peptide and internal standard are used for quantification. Absolute specificity is achieved by mass spectrometric sequencing of the detected peptide.

Binding capacity of the Protein G Dynabeads was determined according to the manufacturer's specifications, and an excess of beads was used in these iMALDI experiments to ensure maximum binding of the antibody. While linearity of the assay over a higher concentration range has not yet been assessed, samples may be diluted to fall within the linear range if necessary. It is also important to note that, because angiotensin I is already of appropriate size for affinity capture and MALDI analysis, digestion of the plasma is not necessary. Beads were washed three times in $25 \mathrm{mM}$ ammonium bicarbonate $(25-\mu \mathrm{L}$ aliquots), and then resuspended in $5 \mu \mathrm{L} 25 \mathrm{mM}$ ammonium bicarbonate. A 1- $\mu \mathrm{L}$ aliquot of the bead slurry was spotted on the MALDI target. The peptide was eluted from the immobilized antibody beads on the MALDI target, with $10 \mathrm{mM}$ $\alpha$-cyano-4-hydroxycinnamic acid (CHCA) in $0.1 \%$ trifluoroacetic acid. MS and MS/MS analyses were performed on an Applied Biosystems (Foster City, CA, USA) 4800 MALDI TOF/TOF mass spectrometer.

In development of this iMALDI assay for the quantitation of angiotensin I, a $5-\mu \mathrm{L}$ aliquot of Protein G Dynabead slurry was incubated with $2 \mu \mathrm{L}$ of polyclonal rabbit anti-angiotensin antibody and $20 \mu \mathrm{L}$ of plasma. Stable isotopically-labeled angiotensin I was spiked in as an internal standard. The affinity beads were then washed and spotted directly onto a stainless steel
MALDI target for MS analysis, followed by MS/MS analysis, which provides sequence information and confirmation that the correct peptide has been detected and quantitated.

To generate a calibration curve, 250 fmol SIS angiotensin I was spiked into each sample, and varying amounts of unlabeled angiotensin I were added $(0-2500$ fmol). Unlabeled angiotensin I and SIS peptide were captured by monoclonal antibody affinity beads using our iMALDI method. The ratios of the unlabeled to labeled angiotensin I ions were normalized to the signal from the SIS peptide.

\section{Results and Discussion}

\section{iMALDI Results}

Angiotensin I in buffer. Using the iMALDI approach, we were able to improve the limit of detection of angiotensin I compared with direct MALDI mass spectrometric analysis of the peptide in solution. Figure 2a shows the spectrum obtained from $4 \mathrm{fmol} / \mu \mathrm{L}$ angiotensin I in 5\% acetonitrile/0.1\% TFA solution, spotted directly on the MALDI target (4 fmol on target). In contrast, Figure $2 \mathrm{~b}$ shows the improved sensitivity afforded by the iMALDI capture of angiotensin I from $50 \mu \mathrm{L}$ of a $50 \mathrm{amol} / \mu \mathrm{L}(65 \mathrm{pg} / \mathrm{mL})$ solution in PBS 

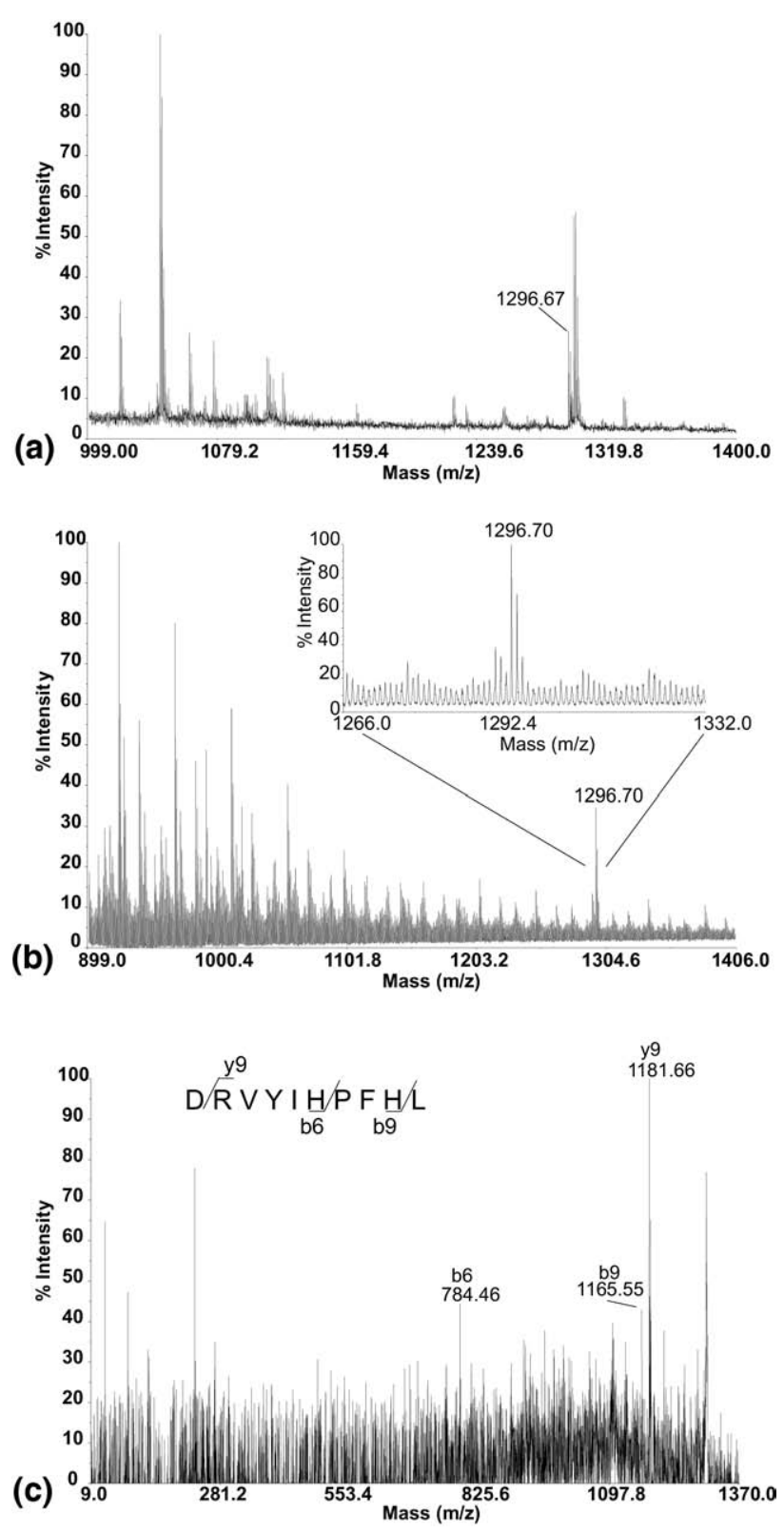

Figure 2. Improved sensitivity in the detection of angiotensin I by MALDI TOF MS provided by the iMALDI approach. (a) Four fmol angiotensin I in 5\% acetonitrile/0.1\% TFA solution; (b) 2500 amol of angiotensin I in 50 uL PBS buffer was detected by iMALDI (500 amol on target); (c) MS/MS of $500 \mathrm{amol} / \mu \mathrm{L}$ on-target angiotensin I.

buffer, which corresponds to $500 \mathrm{amol}$ on target. This represents an 80-fold improvement in sensitivity of the assay for angiotensin I by using by iMALDI $(4 \mathrm{fmol} / \mu \mathrm{L}$ versus $50 \mathrm{amol} / \mu \mathrm{L}$ ). Figure $2 \mathrm{c}$ shows the MS/MS spectrum of angiotensin I from this PBS solution, using iMALDI enrichment. Although the ion signals are not very intense, with a low signal to noise ratio $(\mathrm{S} / \mathrm{N}$ : $8-28$ ) in the MS/MS analysis, the strongest fragment ions $\left(b_{6}, b_{9}\right.$, and $\left.y_{9}\right)$ are observed in a similar pattern to that seen with MS/MS analysis of higher concentrations of angiotensin I. The mass accuracy of the fragment ions
(20-160 ppm) also falls within the expected range for MALDI TOF/TOF analysis of complex samples using this instrument.

Angiotensin I in plasma. Figure 3 shows various stages in the development of the iMALDI assay. When whole (i.e., non-digested) human plasma from a donor patient was analyzed directly by MALDI-TOF MS after a 1-h angiotensin I generation period, angiotensin I $(\mathrm{m} / z$ 1296) was not detected (Figure 3a, the arrow indicates the absence of a peak at the $\mathrm{m} / \mathrm{z}$ value corresponding to angiotensin I). Whole human plasma was incubated with Protein G Dynabeads without antibody to determine nonspecific binding of angiotensin I to the beads (Figure 3b).

Endogenous angiotensin I was detectable (Figure 3c) using the iMALDI approach, even without an angiotensin I generation period. As expected, a stronger signal for angiotensin I was obtained after a 1-h angiotensin I generation period at $37^{\circ} \mathrm{C}$ (Figure 3d). Specific fragment ions of angiotensin I were obtained by performing MS/MS of the $\mathrm{m} / \mathrm{z} 1296$ ion from this spectrum (Figure 3e). Only $20 \mu \mathrm{L}$ of plasma was used in these experiments, and the angiotensin I capture period was performed overnight $(12-18 \mathrm{~h})$ at $4{ }^{\circ} \mathrm{C}$ with the immobilized antibody beads.

It should be noted that considerable background signal is observed in the MS spectra shown in Figure 2b, Figure $3 b, c$, and $d$, which is caused by the Tween 20-containing buffer that the Protein G Dynabeads are stored in. While Tween aids in sample handling by preventing loss of beads, which might otherwise stick to the walls of the tube, it is detected by the mass spectrometer as a repeating series of peaks resulting in background signals that can interfere with the detection of low-abundance peptides such as angiotensin I. In contrast, CHAPS detergent is detected as a single peak, which can help reduce the possibility of interference with the detection of target peptides. We have previously shown that an exchange of Tween 20 buffer with CHAPS $(0.3 \%$ CHAPS, $1 \times$ PBS) buffer helps to reduce background noise and improves sensitivity, and a manuscript describing this work is currently in preparation [7]. The Tween/CHAPS exchange, however, does not result in complete removal of Tween, so the use of detergent-free beads is preferred. Invitrogen Dynal AS, Norway, kindly provided us with prototype Protein G Dynabeads prepared without Tween. Figure $3 \mathrm{f}$ shows that even without an angiotensin I generation period, the level of endogenous angiotensin I can be quantitated in $20 \mu \mathrm{L}$ of whole plasma by iMALDI when these prototype beads are used. A comparison of Figure $3 b$, c, and d with Figure $3 f$ shows that by using these Tween-free beads, the background signals are considerably reduced.

The linearity of this assay was assessed by adding a constant amount of isotopically-coded internal standard to whole human plasma, and increasing amounts of a synthetic peptide representing the endogenous form 
(a)
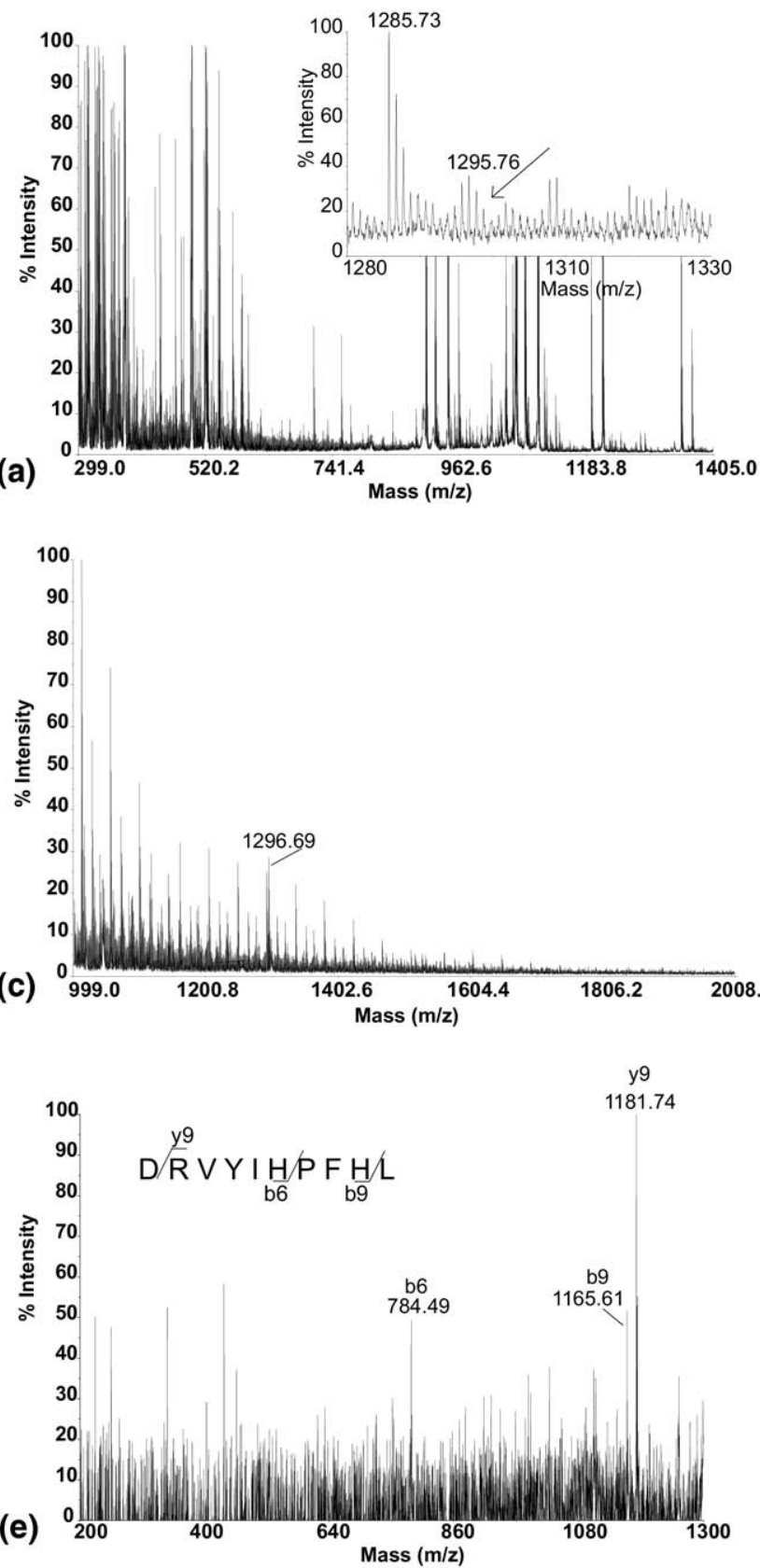
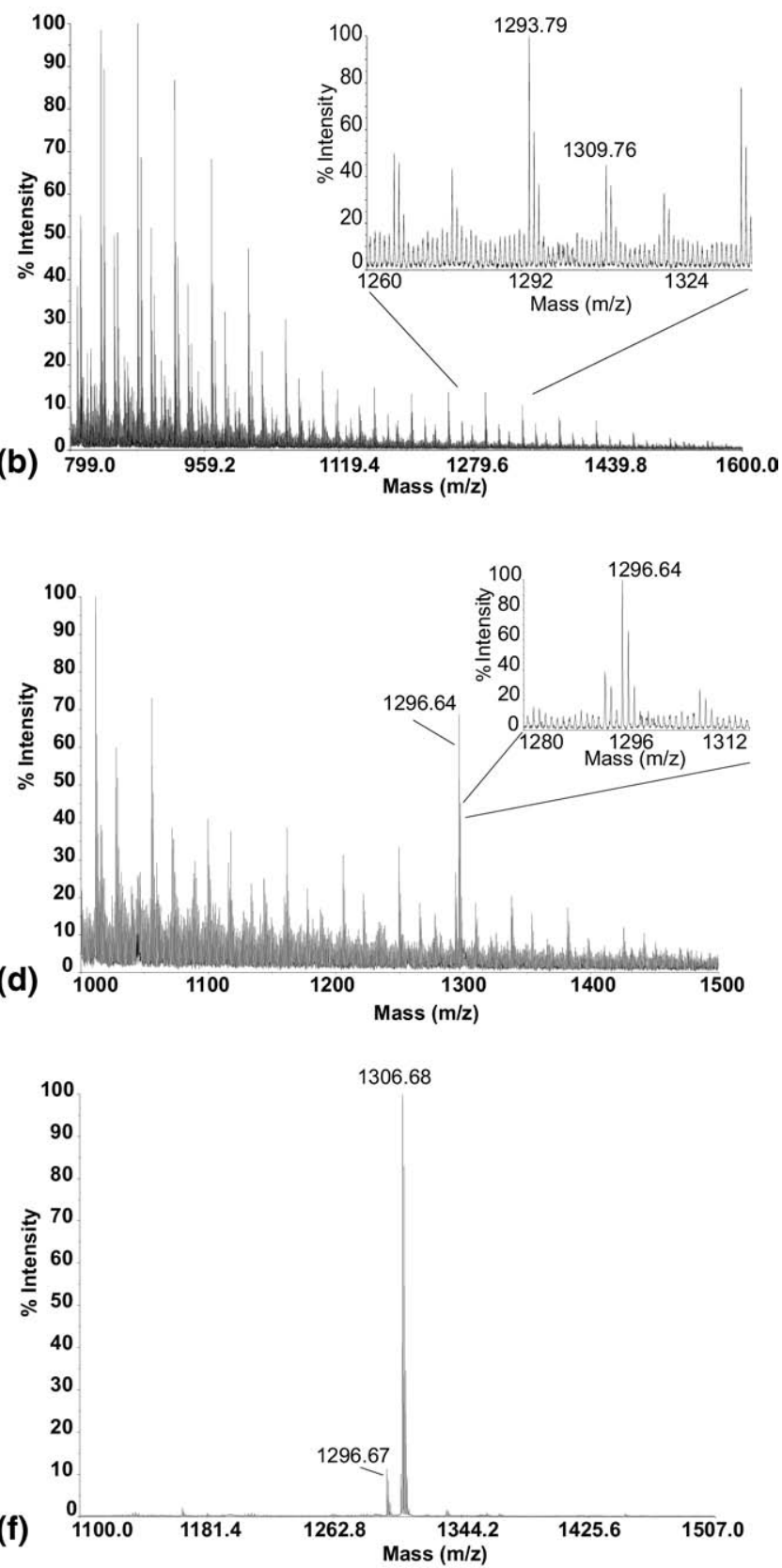

Figure 3. Detection and quantitation of angiotensin I in plasma at various stages in the development of the iMALDI assay. Plasma samples were incubated overnight at $4{ }^{\circ} \mathrm{C}$ with immobilized antibody beads and analyzed by MALDI MS. (a) Angiotensin I was not detected in human plasma spotted directly on the MALDI target without prior enrichment on anti-angiotensin beads; (b) nonspecific binding of angiotensin I was not observed when $20 \mu \mathrm{L}$ human plasma was incubated with Protein G Dynabeads (without antibody or added SIS peptide); (c) endogenous angiotensin I from the same patient sample was detected in $20 \mu \mathrm{L}$ human plasma without an angiotensin I generation period, using anti-angiotensin antibody bound to standard Protein G Dynabeads (no SIS peptide added); (d) endogenous angiotensin I from the same patient sample was detected in $20 \mu \mathrm{L}$ human plasma, after a 1-h angiotensin I generation period at $37^{\circ} \mathrm{C}$, using anti-angiotensin antibody bound to standard Protein G Dynabeads (no SIS peptide added); (e) MS/MS spectra showing sequence ions from the $\mathrm{m} / \mathrm{z} 1296$ ion from (d); (f) detection of endogenous levels of angiotensin I in a patient sample without an angiotensin I generation period, and SIS peptide added, using anti-angiotensin antibody bound to detergent-free Protein G Dynabeads.

(Figure 4). The concentration curve shows that the assay is linear from 0 to $125 \mathrm{fmol} / \mu \mathrm{L}$ of added angiotensin I with a correlation coefficient of 0.98 when synthetic angiotensin $\mathrm{I}$ is added to plasma. The peak heights for the angiotensin
I peptide have been normalized to the peak height from the SIS standard. The inset shows how the line can be extrapolated back to the $x$-intercept to give the concentration of angiotensin I in the original sample. 


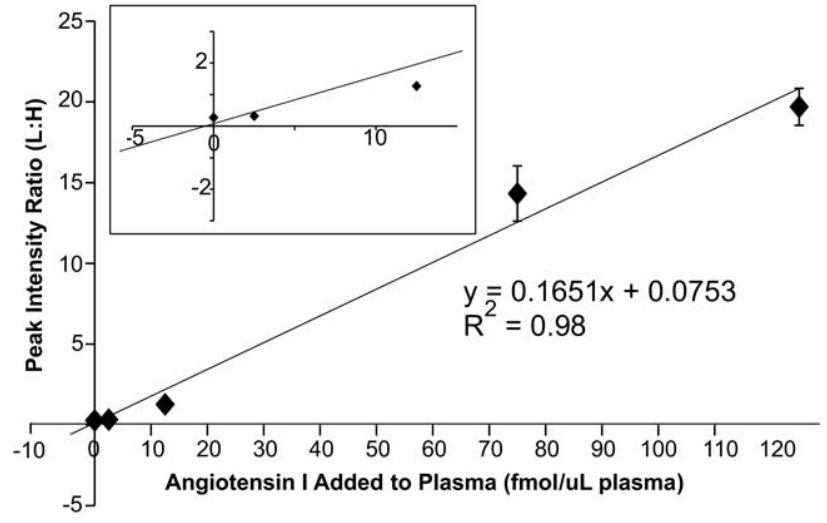

Figure 4. Quantitation of angiotensin I in plasma by iMALDI. Standard curve showing the linear response of iMALDI to varying levels of angiotensin I, spiked into a $20 \mu \mathrm{L}$ plasma sample. Two hundred and fifty fmol SIS angiotensin I was spiked into each sample, and the ratios were normalized to the signal from the SIS peptide. The inset shows how the line can be extrapolated back to the $x$-intercept, which gives the concentration of angiotensin I in the original sample.

\section{Comparison of iMALDI and RIA for Determination of PRA}

Time required. The standard method for determining PRA measures the amount of angiotensin I produced from 50 to $500 \mu \mathrm{L}$ [12] of plasma during a 1-h angiotensin generation period at $37^{\circ} \mathrm{C}$. At the same time, the same sample is also incubated for $1 \mathrm{~h}$ at $4{ }^{\circ} \mathrm{C}$ to provide a "zero" value. For samples with very low renin activities, angiotensin I generation periods of 3 or $18 \mathrm{~h}$ may be required [13]. After angiotensin I is produced, it is measured by competitive RIA, which requires a second 48- to 72 -h incubation at $4{ }^{\circ} \mathrm{C}$. The difference in the concentration of angiotensin I in samples incubated at $37^{\circ} \mathrm{C}$ and $4{ }^{\circ} \mathrm{C}$ is used to calculate PRA, expressed as amount of angiotensin I (ng) per $\mathrm{mL}$ per hour.

The iMALDI protocol for the measurement of angiotensin I, as described in this paper, enabled the detection of endogenous levels of angiotensin $\mathrm{I}$ in donor plasma samples (Figure 3c, d, and f) without a 1-h angiotensin I generation period. Only $20 \mathrm{uL}$ of plasma was required for these experiments. In a PRA assay, it might be possible to shorten the angiotensin I generation period by increasing the volume of plasma. After the angiotensin generation period, the plasma is incubated with immobilized antibody overnight, during which time the anti-angiotensin I antibody binds both the endogenous angiotensin I and the non-radioactive SIS standard peptide (angiotensin I capture period). The absolute amount of angiotensin I is determined by MALDI-MS analysis, and the MALDI data acquisition only takes $\sim 2 \mathrm{~s}$ per spot.

Calibration curve. Sandwich assays are not suitable for measurement of small molecules like angiotensin I because the analyte is not large enough to bind two separate antibodies. Instead, single antibody competi- tive binding assays are used, where the endogenous analyte and a radiometrically-labeled analyte are incubated together with an antibody that will bind both. The resulting calibration curve is sigmoidal in shape, thereby limiting the linear range of competitive binding assays (such as PRA) by RIA.

The reported range for low to high angiotensin I production in plasma is $0.2 \mathrm{ng} / \mathrm{mL} / \mathrm{h}$ to $13.5 \mathrm{ng} / \mathrm{mL} / \mathrm{h}$, respectively, with an average of $1.6 \mathrm{ng} / \mathrm{mL} / \mathrm{h}$ [14]. A 1-h angiotensin I generation period would result in a final plasma concentration of $\sim 150$ to 10,400 attomol/ $\mu \mathrm{L}$. Even with our current version of the assay, which measures the amount of angiotensin in one-fifth of the original $20 \mu \mathrm{L}$ of plasma in each well on the MALDI plate, the sensitivity of the iMALDI assay should be sufficient to detect lower levels of angiotensin I, especially if detergent-free beads were used. Moreover, the calibration curve for angiotensin I in plasma is linear over the expected range in clinical samples, which is a significant advantage for accurate quantitation.

\section{Conclusions}

In this paper, we demonstrate the use of iMALDI $[3,4$, $7,9-11]$ for the sensitive and specific quantitation of angiotensin I in human plasma. Using iMALDI, angiotensin I is measurable in $20 \mu \mathrm{L}$ whole plasma even without an angiotensin I generation period. With a 1-h angiotensin I generation period at $37^{\circ} \mathrm{C}$ the concentration of angiotensin I is increased, especially when ACE inhibitors are included as in a typical PRA assay. Although the measurement of angiotensin I in human plasma as described in this paper is not an assay for PRA, it is the essential "first step" in determining if such an assay is feasible.

The iMALDI-based calibration curve was linear over a 50-fold concentration range (from 0.2 to $3 \mathrm{ng}$ in $20 \mu \mathrm{L}$ ), and thus already comes close to fulfilling the clinical requirement for a linear calibration curve over a 60 -fold concentration range for angiotensin I. The linearity of this response results from the ability to normalize the response for angiotensin I to the response for the constant amount of SIS angiotensin I in each sample. Since only $20 \mu \mathrm{L}$ of plasma was used in this assay, the limit of detection could easily be decreased by simply incubating the affinity beads with an increased volume of plasma, or using non-Tween-containing beads, which would reduce the chemical background, or by increasing the angiotensin I generation period. The iMALDI angiotensin I assay, therefore, has the potential to improve upon the current PRA assay by eliminating the need for radioactive labels, while providing absolute quantitation, absolute specificity, and high sensitivity.

We originally created the calibration curve shown in Figure 4 to determine the linear range of detection using iMALDI. However, this experiment is actually a form of "standard addition," and allows the accurate determination of angiotensin I in the original sample. This 
method could be useful for samples with very low levels of angiotensin I, or in the unlikely event that there happened to be an interfering background ion. The sensitivity of the iMALDI approach and the speed of the MALDI-MS acquisition actually makes it feasible to perform this very accurate standard-addition assay on every sample, simply by adding a constant amount of SIS peptide and a series of known amounts of unlabeled synthetic peptide to different aliquots.

It has been hypothesized that there should be a correlation between the absolute concentrations of angiotensin I and angiotensin II, and PRA [15]. Because iMALDI can easily be "multiplexed," it should be possible to monitor multiple analytes in the same plasma sample. We are currently exploring the possibility of multiplexing this technique by adding additional peptides that are involved in the RAAS, including angiotensin II, to this iMALDI assay. We believe that the high sensitivity of the iMALDI approach will allow us to reduce the time for both incubation steps required for functional assays of PRA, and to simply perform measurements of the absolute quantity of angiotensin I and angiotensin II in the plasma at a few early time points, thereby improving time-to-result by many hours and offering a new approach for screening disorders of the RAAS pathway. With careful handling of the patient samples, the use of appropriate peptidase inhibitors, and the addition of SIS peptides and antibodies for both angiotensin I and angiotensin II, the iMALDI method may permit accurate quantitation of both peptides. In fact, it may be possible to use a single antibody to capture both peptides since angiotensin II is simply a cleaved product of angiotensin I, differing by two amino acids. We have demonstrated the co-capture of closely-related peptides in a previous study on EGFR [16]. In addition, in other experiments, we have observed cross reactivity of this anti-angiotensin I polyclonal antibody with angiotensin II (data not shown). However, angiotensin II was not detected in the experiments described here, which may be a result of the analytical sensitivity of our assay and/or degradation of angiotensin II by peptidases. Measuring both angiotensin I and angiotensin II in the same sample would allow us to determine whether a correlation between angiotensin I and angiotensin II concentration could form the basis for a new diagnostic assay for hypertension.

PRA assays by RIA are widely used for clinical diagnosis of hypertension, and have been well characterized to ensure accurate and precise results, including blood collection protocols and sample handling, angiotensin I generation periods, optimal $\mathrm{pH}$, and enzyme kinetics. However, the current assay is less reliable for low levels of angiotensin I, and involves significant incubation times ("angiotensin I capture period" and "angiotensin I generation period"). The assay also results in a sigmoidal calibration curve with a short linear range, which limits its accuracy. When placing a new assay for PRA into a clinical setting, such as this iMALDI assay, current blood collection and sample handling protocols should be followed. Additional considerations before implementation of our iMALDI assay for PRA in a clinical setting include determining the lowest limit of detection, reproducibility, multiplexing capabilities of multiple RAAS peptides, and validation of the iMALDI method against current RIA protocols.

\section{Acknowledgments}

A patent for iMALDI technology has been submitted by the University of North Carolina (C.H.B.): Methods of Quantitation and Identification of Peptides and Proteins. Canadian patent application no. 2507,864, Filing date 2003-12-02. U.S. patent application number 20040214338, filing date April 12, 2003.

Funds for this research were generously provided by Genome British Columbia and Genome Canada. We would like to thank Dr. Leigh Anderson (Plasma Proteome Institute) and Dr. Terry Pearson and Morty Razavi (University of Victoria) for support in the development of bead-based assays. We would also like to thank Invitrogen for providing prototype detergent-free beads for the purpose of developing this iMALDI assay.

\section{References}

1. Chobanian, A. V.; Bakris, G. L.; Black, H. R.; Cushman, W. C.; Green, L. A.; Izzo, J. L. J.; Jones, D. W.; Materson, B. J.; Oparil, S.; Wright, J. T. J.; Roccella, E. J. Joint National Committee on Prevention, Detection, Evaluation, and Treatment of High Blood Pressure. National Heart, Lung, and Blood Institute; National High Blood Pressure Education Program Coordinating Committee. Seventh Report of the Joint National Committee on Prevention, Detection, Evaluation, and Treatment of High Blood Pressure. Hypertension 2009, 42, 1206-1252.

2. Don, B. R.; Schambelan, M.; Lo, J. C. Endocrine Hypertension. In Basic and Clinical Endocrinology, 7th ed; Lange Medical Books/McGraw Hill: Toronto, 2004; p. 414-438.

3. Jiang, J.; Parker, C. E.; Hoadley, K. A.; Perou, C. M.; Boysen, G.; Borchers, C. H. Development of an Immuno Tandem Mass Spectrometry (iMALDI) assay for EGFR diagnosis. Proteom. Clin. Appl. 2007, 1, 1651-1659.

4. Jiang, J.; Parker, C. E.; Fuller, J. R.; Kawula, T. H.; Borchers, C. H. An Immunoaffinity Tandem Mass Spectrometry (iMALDI) Assay for Detection of Francisella tularensis. Anal. Chim. Acta 2007, 605, 70-79.

5. Goodfriend, T. L.; Levine, L.; Fasman, G. D. Antibodies to Bradykinin and Angiotensin: A Use of Carbodiimides in Immunology. Science 1964, 144, 1344-1346.

6. Bordeerat, N. K.; Georgieva, N. I.; Klapper, D. G.; Collins, L. B.; Cross, T. J.; Borchers, C. H.; Swenberg, J. A.; Boysen, G. Accurate Quantitation of Standard Peptides Used for Quantitative Proteomics. Proteomics 2009, 9, 3939-3944.

7. Shah, B.; Reid, J. D.; Kuzyk, M. J.; Parker, C. E.; Borchers, C. H. Developing an iMALDI Method. Methods Mol. Biol. 2009, unpublished, (submitted for publication).

8. Poulsen, K.; Jorgensen, J. An Easy Radioimmunological Microassay of Renin Activity, Concentration, and Substrate in Human and Animal Plasma and Tissues Based on Angiotensin Trapping by Antibody. J Clin. Endocrinol. Metab. 1974, 39, 816-825.

9. Reid, J. D.; Parker, C. E.; Borchers, C. H. Protein Arrays for Biomarker Discovery. Curr. Opin. Mol. Therapeut. 2007, 9, 216-221.

10. Warren, E. N.; Elms, P. J.; Parker, C. E.; Borchers, C. H. Development of a Protein Chip: A MS-Based Method for Quantitation of Protein Expression and Modification Levels Using an Immunoaffinity Approach. Anal. Chem. 2004, 76, 4082-4092.

11. Warren, E. N.; Jiang, J.; Parker, C. E.; Borchers, C. H. A Method for the Absolute Quantitation Of Cancer-Related Proteins Using A MS-Based Peptide Chip. BioTechniques 2005, 38, S7-S11.

12. Hartman, D.; Sagnella, G. A.; Chesters, C. A.; MacGregor, G. A. Direct Renin Assay and Plasma Renin Activity Assay Compared. Clin. Chem. 2004, 50, 2159-2161.

13. Sealey, J. E.; Gordon, R. D.; Mantero, F. Plasma Renin and Aldosterone Measurements in Low Renin Hypertensive States. Trends Endocrinol. Metab. 2005, 16, 86-91.

14. Locsei, Z.; Racz, K.; Patocs, A.; Kovacs, G. L.; Toldy, E. Influence of Sampling and Storage Conditions on Plasma Renin Activity and Plasma Renin Concentration. Clin. Chim. Acta 2009, 402, 203-205.

15. Lijnen, P. J.; Amery, A. K.; Fagard, R. H. Endogenous Angiotensin I Concentration in Human Plasma. J. Lab. Clin. Med. 1978, 92, 353-362.

16. Shah, B.; Borchers, C. H. iMALDI: A Targeted Proteomics Approach to the Differentiation of EGFR and Its Isoforms. Proceedings of the 57th ASMS Conference on Mass Spectrometry and Allied Topics; Philadelphia, PA, May 31-June 4; 2009. 